\title{
Incremental short daily home hemodialysis: a case series
}

Stephanie M. Toth-Manikowski ${ }^{1}$, Surekha Mullangi ${ }^{1}$, Seungyoung Hwang ${ }^{1}$ and Tariq Shafi ${ }^{1,2,3^{*}}$ (D)

\begin{abstract}
Background: Patients starting dialysis often have substantial residual kidney function. Incremental hemodialysis provides a hemodialysis prescription that supplements patients' residual kidney function while maintaining total (residual + dialysis) urea clearance (standard Kt/Nurea) targets. We describe our experience with incremental hemodialysis in patients using NxStage System One for home hemodialysis.

Case presentation: From 2011 to 2015, we initiated 5 incident hemodialysis patients on an incremental home hemodialysis regimen. The biochemical parameters of all patients remained stable on the incremental hemodialysis regimen and they consistently achieved standard Kt/Nurea targets. Of the two patients with follow-up $>6$ months, residual kidney function was preserved for $\geq 2$ years. Importantly, the patients were able to transition to home hemodialysis without automatically requiring 5 sessions per week at the outset and gradually increased the number of treatments and/or dialysate volume as the residual kidney function declined.

Conclusions: An incremental home hemodialysis regimen can be safely prescribed and may improve acceptability of home hemodialysis. Reducing hemodialysis frequency by even one treatment per week can reduce the number of fistula or graft cannulations or catheter connections by $>100$ per year, an important consideration for patient well-being, access longevity, and access-related infections. The incremental hemodialysis approach, supported by national guidelines, can be considered for all home hemodialysis patients with residual kidney function.
\end{abstract}

Keywords: Residual kidney function, Incremental hemodialysis, Home hemodialysis, Uremic toxins, Kt/N, NxStage

\section{Background}

Over a million people are expected to initiate hemodialysis in the US in the next decade [1]. Home dialysis is widely considered to be the preferred dialysis modality, with some estimates considering $>25 \%$ of the incident patients eligible for home dialysis [2]. However, in 2014 only $7.8 \%$ of the 115,363 incident dialysis patients in the U.S. initiated dialysis using a home modality and only $0.3 \%$ of all patients were started on dialysis using home hemodialysis [1]. NxStage System One (NxStage Medical, Inc., Lawrence, MA) is the most widely used short daily home hemodialysis system in the US and hemodialysis using this system is typically prescribed 5 days per week.

\footnotetext{
* Correspondence: tshafi@jhmi.edu

'Division of Nephrology, Johns Hopkins University School of Medicine, 301

Mason Lord Drive, Suite 2500, Baltimore, MD 21224, USA

${ }^{2}$ Welch Center for Prevention, Epidemiology and Clinical Research, Johns

Hopkins University, Baltimore, MD, USA

Full list of author information is available at the end of the article
}

Most patients starting dialysis have substantial residual kidney function that can contribute to solute clearance and volume homeostasis [3]. Presence of residual kidney function is independently associated with improved survival and quality of life in incident hemodialysis patients $[4,5]$. Incremental hemodialysis is an individualized hemodialysis prescription that adjusts the dialysis dose (dialysis Kt/Vurea) by accounting for residual kidney function (residual Kt/Vurea) [6-8]. In patients with significant residual kidney function receiving in-center hemodialysis, incremental hemodialysis prescription is associated with similar survival but longer preservation of residual kidney function, compared to routine thrice weekly hemodialysis [9]. However, there are no data on incremental hemodialysis prescription for home hemodialysis patients in the present era. The flexibility of home hemodialysis scheduling and the substantial residual kidney function in incident hemodialysis patients makes incremental home hemodialysis prescription particularly attractive in this population [3]. 
Starting 2011, we implemented an incremental home hemodialysis protocol at a home hemodialysis unit affiliated with Johns Hopkins University in Baltimore, Maryland (Fig. 1). In this case series, we describe the characteristics, dialysis dosing, laboratory parameters, and outcomes of the first five patients with residual kidney function treated with incremental home hemodialysis using NxStage System One.

\section{Case presentation}

We retrospectively identified patients treated with incremental hemodialysis and abstracted their data from the electronic medical record. We followed patients from the start of hemodialysis in our center to the end of the study period (December 17, 2015), transfer to another unit, kidney transplantation or death. The Johns Hopkins Medicine Institutional Review Board reviewed and approved this study with waiver of consent for the retrospective review.

The protocol for incremental home hemodialysis is presented in Fig. 1. We measured residual renal function using a 24-h urine collection immediately preceding the dialysis session for monthly labs. The central laboratory for the large dialysis organization uses a factor of $0.9^{*}$ predialysis-urea level to calculate the residual urea clearance and residual stdKt/Vurea. The laboratory also reports dialysis stdKt/Vurea calculated using data from the modeling session and the number of prescribed

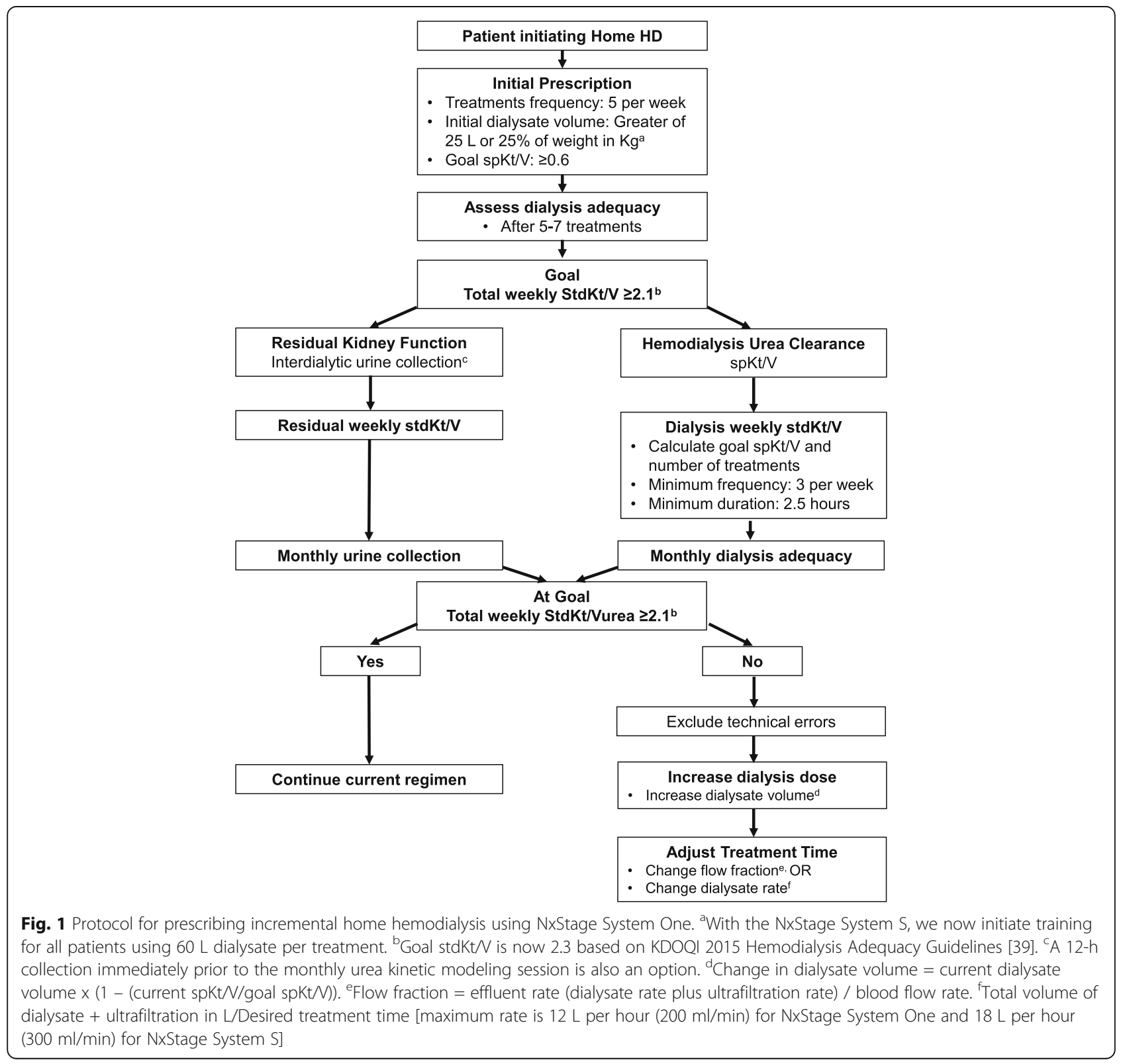


dialysis treatments, using equation recommended by the 2006 KDOQI hemodialysis adequacy guidelines [10]. We calculated the total weekly stdKt/Vurea as the sum of residual stdKt/Vurea and dialysis stdKt/Vurea. In general, when a new dialysate volume was calculated, we rounded it up to optimize the use of dialysate bags or the prepared dialysate batch. On NxStage System One, the treatment time is mainly determined by the dialysate volume, blood flow rate, and ultrafiltration volume. Since the blood flow rate is generally constant, the dialysate volume determines the treatment time, which can be modified by adjusting the flow fraction (effluent rate/blood flow rate). Higher flow fraction increases the dialysate flow rate and shortens treatment time. The effluent rate (dialysate rate + ultrafiltration rate) is the limiting factor in this step [maximum of $12 \mathrm{~L} / \mathrm{h}(200 \mathrm{ml} /$ min) for NxStage System One and $18 \mathrm{~L} / \mathrm{h}(300 \mathrm{ml} / \mathrm{min})$ for NxStage System S].

We treated 5 incident dialysis patients with residual kidney function using this incremental regimen. Patient characteristics, dialysis parameters, and laboratory test results are presented in Table 1 . Of the two patients with follow-up $>6$ months, residual kidney function was preserved for $\geq 2$ years. The biochemical parameters of all patients remained stable. Importantly, the patients were able to transition to home hemodialysis without automatically requiring 5 sessions per week at the outset and gradually increased the number of treatments and/or dialysate volume as the residual kidney function declined. A brief description of the individual patients follows:

Patient 1: This patient initiated home hemodialysis training using NxStage System One 5 days per week. The baseline 24-h urine volume was $1000 \mathrm{~mL} /$ day with a urinary urea clearance of $3 \mathrm{~mL} / \mathrm{min}$ corresponding to a weekly renal stdKt/V of 0.72 . Hemodialysis frequency was decreased to 4 treatments per week. Over time, as the residual urea clearance declined, dialysis urea clearance was increased by increasing the dialysate volume. By using this incremental approach to dialysis, we were able to achieve urea clearance targets with 4 treatments per week, instead of 5 treatments per week, which would have been necessary if we ignored residual function. As a result, the patient was able to avoid $>200$ cannulations of the fistula over a period of 2 years ( 1 less treatment per week equals 2 less cannulations per week * 52 weeks * 2 years). Reducing the number of cannulations was an important quality of life consideration for this patient, which we were able to achieve using an incremental regimen.

Patient 2: This patient was transferred to the home hemodialysis program from recently initiated in-center hemodialysis. The initial urine volume was $1600 \mathrm{~mL} /$ day with a urinary urea clearance of $4.1 \mathrm{~mL} / \mathrm{min}$ and a weekly renal stdKt/V of 1.19 . Home hemodialysis was started using NxStage System One with 3 treatments per week schedule (every other day). The patient maintained residual kidney function until undergoing kidney transplantation 2 years after hemodialysis initiation. Using an incremental approach, allowed this patient to avoid $>200$ cannulations while undergoing home hemodialysis ( 1 less treatment per week equals 2 less cannulations per week * 52 weeks * 2 years).

Patient 3: This patient underwent timed urine collection prior to hemodialysis initiation. The initial urine volume was $700 \mathrm{~mL} /$ day with a renal stdKt/V of 1.05 . Home hemodialysis was initiated with 3 treatments per week, increasing to 4 per week as the residual kidney function declined. Follow-up data is only reported to 6 months as contractual issues led to closure of the clinic where the patient was under treatment.

Patient 4: This was a morbidly obese patient who started home hemodialysis for intractable volume overload. The initial urine volume, on diuretics, was $2200 \mathrm{~mL} /$ day with a urinary urea clearance of $11.5 \mathrm{~mL} / \mathrm{min}$ and renal stdKt/V of 1.66. Dialysis was initiated using home hemodialysis with a 5 days per week regimen due to volume overload. Using an incremental approach allowed the patient to maintain adequate clearance with the use of a lower dialysate volume $(30 \mathrm{~L})$, with a shorter treatment time than what would have been required if residual kidney function was ignored. At 6 months after dialysis initiation, the patient moved out of the area due to employment reasons and was transferred to another home hemodialysis program.

Patient 5: This patient was on in-center maintenance hemodialysis who sought personalized care as the patient had noticed significant urine volume. The baseline urine volume was $750 \mathrm{~mL} /$ day with a urinary urea clearance of $6.98 \mathrm{~mL} / \mathrm{min}$ and weekly stdKt/V of 1.38 . The patient started home hemodialysis with 3 times per week schedule (every other day). The follow-up data is only reported to 6 months as contractual issues led to closure of the clinic where the patient was under treatment.

\section{Discussion}

There are several key points highlighted by this case series. First, an incremental regimen can improve patient acceptability of home hemodialysis and make the transition to home hemodialysis easier. It allows for titration of dialysis dose on an individual basis and enables patients to remain in control over how and when they perform hemodialysis in the home, very different from the one-size-fits-all approach used for patients undergoing thrice-weekly in-center hemodialysis. Second, less frequent cannulation of vascular access means lowering the number of access cannulations by $>100$ per year (assuming 1 less treatment per week equals 2 less cannulations per week * 52 weeks per year). This is an 


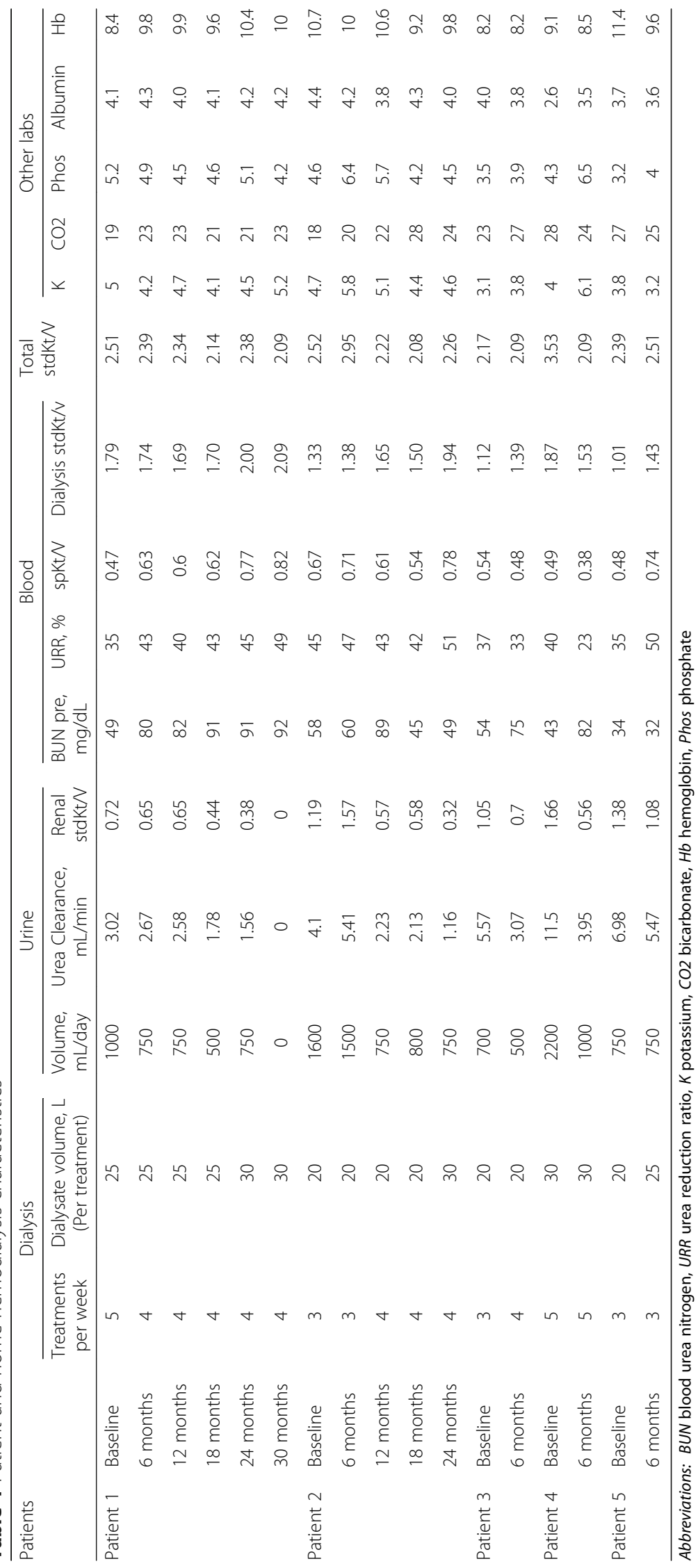


important consideration for patients' quality of life by reducing pain and discomfort with cannulation, and it may also reduce the risk of access complications and blood stream infections. Third, the preserved residual kidney function in the two patients with $>6$ months of follow-up is encouraging. It is interesting to note that the NxStage System uses ultrapure dialysate which has been associated with reduced inflammation and slower residual kidney function decline [11-13]. Applying an incremental approach to home hemodialysis offers a unique advantage to the patient on various fronts. It is tantamount to personalized medicine for the dialysis patient and equips the nephrologist with a patient-centered approach to what has historically been a rather regimented thrice-weekly hemodialysis prescription. Additionally, it has the potential to reduce cost of care to both the patient and the healthcare system without affecting dialysis adequacy.

The importance of residual kidney function preservation cannot be emphasized enough [14-16]. While it is well known that residual kidney function is independently associated with improved survival, patients also report improved healthcare-related quality of life, have better volume and blood pressure control, improved phosphate and potassium clearance, and reduced erythropoietin requirements. Perhaps most importantly, native kidney function allows for excretion of uremic solutes that hemodialysis does not adequately remove [17]. Many of these uremic solutes are potential uremic toxins that contribute to morbidity and mortality in hemodialysis patients $[4,18-20]$.

Previous observational studies suggest that twiceweekly hemodialysis using an incremental approach to hemodialysis initiation results in preserved residual kidney function $[9,21,22]$. Incremental hemodialysis is widely practiced outside the U.S. [22-34] and is now gaining acceptability in the U.S. [35]. While the benefits of frequent hemodialysis on volume overload and left ventricular hypertrophy are well described in anuric prevalent hemodialysis patients, [36] there remain concerns with the effect of frequent hemodialysis in incident hemodialysis patients with residual kidney function. In the Frequent Hemodialysis Network Trials, more frequent hemodialysis was associated with a faster loss of residual kidney function [37]. Additionally, benefit of frequent hemodialysis on left ventricular mass reduction was most evident in patients without residual kidney function at baseline; 8 of 9 patients with a pronounced reduction in LV mass in the Daily Trial were anuric [38]. Frequent hemodialysis also increased the risk of access complications, [39] prompting caution in the 2015 KDOQI hemodialysis adequacy guidelines [40]. These findings call into question the conventional approach of one-size-fits-all dialysis regimen without consideration of residual kidney function, particularly in incident hemodialysis patients $[3,7]$.
One practical limitation to the use of incremental home hemodialysis is the requirement of monthly timed urine collections. Although the KDOQI guidelines recommend these measurements to be done quarterly if incremental dialysis is prescribed, [10] we elected to monitor it monthly to ensure adequate solute clearance. All patients were quite willing to perform monthly 24-h urine collections as the results had meaningful impact on their treatment. Generally, the timed urine collection is done over the entire interdialytic interval with blood samples for urea collected at the end of the hemodialysis treatment when urine collection is started and at the beginning of the next hemodialysis treatment when urine collection ends [10]. However, there are several limitations of this technique including its onerous nature and chances for errors during collection. Additionally, residual kidney function is not at steady state in the interdialytic period. It is the lowest at the end of hemodialysis, presumably from volume depletion, and the highest at the end of the interdialytic interval, as shown in an elegant study by van Olden et al. [41]. These authors recommended that the best approach to measuring residual kidney function may be timed urine collection for $12 \mathrm{~h}$ prior to start of hemodialysis and a single blood sample at the end of urine collection interval (start of hemodialysis) [41]. An alternative approach without requiring urine collection is to estimate residual kidney function from serum markers, similar to estimating GFR from serum creatinine [42]. The low molecular weight proteins such as $\beta$-trace protein (BTP), may be used for estimating residual kidney function in patients undergoing standard high-flux hemodialysis (online calculator: http:// www.ureaclearance.org/). BTP is available for clinical use in Europe, but not in the U.S. at the present time.

\section{Conclusions}

Our small case series demonstrates that incremental hemodialysis can be safely used to individualize a dialysis dose and preserve residual kidney function in patients undergoing home hemodialysis. Although our caseseries included a small number of patients, the results were gathered in a real-life clinical setting, and are therefore generalizable to any patient with residual kidney function starting home hemodialysis. Our study adds to a growing body of literature on the use of incremental hemodialysis in the contemporary time period in the U.S. and the rest of the world.

In conclusion, incremental home hemodialysis prescription is simple, feasible, and can be safely prescribed for patients with residual kidney function. The flexibility of home hemodialysis scheduling and the potential benefit of incremental hemodialysis on preservation of residual kidney function makes this an attractive treatment option for patients initiating dialysis. 


\section{Abbreviations}

BTP: $\beta$-trace protein; ESRD: End-stage renal disease; KDOQI: Kidney disease outcomes quality initiative

\section{Acknowledgements}

Not applicable.

\section{Funding}

Dr. Shafi is supported by R03-DK-104012 and R01-HL-132372-01.

Dr. Toth-Manikowski is supported by NIH/NIDDK T32 DK 007732.

\section{Availability of data and materials}

The datasets used and/or analyzed during the current study are available from the corresponding author on reasonable request.

\section{Authors' contributions}

STM and TS designed the study. SM and TS abstracted the data. SH processed and analyzed the data. STM and TS analyzed the data and drafted the manuscript. All authors read and approved the final manuscript.

\section{Ethics approval and consent to participate}

The study was approved by the Johns Hopkins Medicine Institutional Review Board (IRB) with waiver of consent (IRB00090297) and by DaVita Clinical Research.

\section{Consent for publication}

Not applicable. Case series without individually identifiable data.

\section{Competing interests}

Dr. Shafi: consulting fees from Siemens; member of the Editorial Board of BMC Nephrology (Associate Editor); Medical Director, Home Hemodialysis.

\section{Publisher's Note}

Springer Nature remains neutral with regard to jurisdictional claims in published maps and institutional affiliations.

\section{Author details}

'Division of Nephrology, Johns Hopkins University School of Medicine, 301 Mason Lord Drive, Suite 2500, Baltimore, MD 21224, USA. ${ }^{2}$ Welch Center for Prevention, Epidemiology and Clinical Research, Johns Hopkins University, Baltimore, MD, USA. ${ }^{3}$ Department of Epidemiology, Johns Hopkins Bloomberg School of Public Health, Baltimore, MD, USA.

\section{Received: 30 March 2017 Accepted: 30 June 2017}

\section{Published online: 05 July 2017}

\section{References}

1. United States Renal Data. System. 2016 USRDS annual data report: Epidemiology of kidney disease in the United States. National Institutes of Health, National Institute of Diabetes and Digestive and Kidney Diseases, Bethesda, MD, 2016

2. END-STAGE RENAL DISEASE: Medicare Payment Refinements Could Promote Increased Use of Home Dialysis. U.S. Government Accountability Office. GAO-16-125: Published: Oct 15, 2015. Publicly Released: Nov 16, 2015.

3. Shafi T, Mullangi S, Toth-Manikowski SM, Hwang S, Michels WM. Residual kidney function: implications in the era of personalized medicine. Semin Dial. 2017;30(3):241-5

4. Shafi T, Jaar BG, Plantinga LC, Fink NE, Sadler JH, Parekh RS, Powe NR, Coresh J. Association of residual urine output with mortality, quality of life, and inflammation in incident hemodialysis patients: the choices for healthy outcomes in caring for end-stage renal disease (CHOICE) study. Am J Kidney Dis. 2010;56(2):348-58.

5. Termorshuizen F, Dekker FW, van Manen JG, Korevaar JC, Boeschoten EW, Krediet RT. Relative contribution of residual renal function and different measures of adequacy to survival in hemodialysis patients: an analysis of the Netherlands cooperative study on the adequacy of dialysis (NECOSAD)-2. J Am Soc Nephrol. 2004;15(4):1061-70.

6. Golper TA, Mehrotra R. The intact nephron hypothesis in reverse: an argument to support incremental dialysis. Nephrol Dial Transplant. 2015;30(10):1602-4.

7. Basile C, Casino FG, Kalantar-Zadeh K. Is incremental hemodialysis ready to return on the scene? From empiricism to kinetic modelling. J Nephrol. 2017.
8. Golper TA. Incremental Hemodialysis: how I do it. Semin Dial. 2016;29(6):476-80.

9. Obi Y, Streja E, Rhee CM, Ravel V, Amin AN, Cupisti A, Chen J, Mathew AT, Kovesdy CP, Mehrotra R, et al. Incremental Hemodialysis, residual kidney function, and mortality risk in incident dialysis patients: a cohort study. Am J Kidney Dis. 2016;68(2):256-65

10. Hemodialysis Adequacy 2006 Work Group. Clinical practice quidelines for hemodialysis adequacy, update 2006. Am J Kidney Dis. 2006;48(Suppl 1):S2-90.

11. Hsu PY, Lin CL, Yu CC, Chien CC, Hsiau TG, Sun TH, Huang LM, Yang CW. Ultrapure dialysate improves iron utilization and erythropoietin response in chronic hemodialysis patients - a prospective cross-over study. J Nephrol. 2004;17(5):693-700.

12. Schiffl $H$, Lang SM, Fischer R. Ultrapure dialysis fluid slows loss of residual renal function in new dialysis patients. Nephrol Dial Transplant. 2002:17(10):1814-8.

13. Sitter T, Bergner A, Schiffl $\mathrm{H}$. Dialysate related cytokine induction and response to recombinant human erythropoietin in haemodialysis patients. Nephrol Dial Transplant. 2000;15(8):1207-11

14. Wang $A Y M$, Lai KN. The importance of residual renal function in dialysis patients. Kidney Int. 2006;69(10):1726-32.

15. Krediet RT. Preservation of residual kidney function and urine volume in patients on dialysis. Clin J Am Soc Nephrol. 2017;12(3):377-9.

16. Wang AY. Preserving residual kidney function in Hemodialysis patients-back in the spotlight. J Am Soc Nephrol. 2016;27(12):3504-7.

17. Marquez 1O, Tambra S, Luo FY, Li Y, Plummer NS, Hostetter TH, Meyer TW. Contribution of residual function to removal of protein-bound solutes in hemodialysis. Clin J Am Soc Nephrol. 2011:6(2):290-6.

18. Shafi T, Hostetter TH, Meyer TW, Hwang S, Hai X, Melamed ML, Banerjee T, Coresh J, Powe NR. Serum asymmetric and symmetric Dimethylarginine and morbidity and mortality in Hemodialysis patients. Am J Kidney Dis. 2017. doi:10.1053/j.ajkd.2016.10.033.

19. Shafi T, Meyer TW, Hostetter TH, Melamed ML, Parekh RS, Hwang S, Banerjee T, Coresh J, Powe NR. Free levels of selected organic solutes and cardiovascular morbidity and mortality in Hemodialysis patients: results from the retained organic solutes and clinical outcomes (ROSCO) investigators. PLoS One. 2015;10(5):e0126048.

20. Shafi T, Powe NR, Meyer TW, Hwang S, Hai X, Melamed ML, Banerjee T, Coresh J, Hostetter TH. Trimethylamine $\mathrm{N}$-oxide and cardiovascular events in Hemodialysis patients. J Am Soc Nephrol. 2017;28(1):321-31.

21. Vilar E, Wellsted D, Chandna SM, Greenwood RN, Farrington K. Residual renal function improves outcome in incremental haemodialysis despite reduced dialysis dose. Nephrol Dial Transplant. 2009;24(8):2502-10.

22. Zhang M, Wang M, Li H, Yu P, Yuan L, Hao C, Chen J, Kalantar-Zadeh K. Association of initial twice-weekly hemodialysis treatment with preservation of residual kidney function in ESRD patients. Am J Nephrol. 2014;40(2):140-50.

23. Chauhan R, Mendonca S. Adequacy of twice weekly hemodialysis in end stage renal disease patients at a tertiary care dialysis centre. Indian Nephrol. 2015;25(6):329-33.

24. Panaput T, Thinkhamrop B, Domrongkitchaiporn S, Sirivongs D, Praderm L, Anukulanantachai J, Kanokkantapong C, Tungkasereerak P, Pongskul C, Anutrakulchai $S$, et al. Dialysis dose and risk factors for death among ESRD patients treated with twice-weekly hemodialysis: a prospective cohort study. Blood Purif. 2014:38(3-4):253-62.

25. Lei G, Li X, Tu W, Xu C, Duan Z, Wu X. Risk of intradialytic hypotension in patients on thrice-weekly versus twice-weekly hemodialysis. Int J Cardiol. 2014;174(3):821-3.

26. Cheng Y, Tu W, Xiao O Chen Y, Hu L, Wu X. Risk of cardiovascular disease in patients on thrice-weekly versus twice-weekly hemodialysis. Int J Cardiol. 2014;174(3):780-3.

27. Bieber B, Qian J, Anand S, Yan Y, Chen N, Wang M, Zuo L, Hou FF, Pisoni RL, Robinson BM, et al. Two-times weekly hemodialysis in China: frequency, associated patient and treatment characteristics and quality of life in the China dialysis outcomes and practice patterns study. Nephrol Dial Transplant. 2014:29(9):1770-7.

28. Bello BT, Raji YR, Sanusi I, Braimoh RW, Amira OC, Mabayoje OM. Challenges of providing maintenance hemodialysis in a resource poor country: experience from a single teaching hospital in Lagos, Southwest Nigeria. Hemodial Int. 2013;17(3):427-33.

29. Lin X, Yan Y, Ni Z, Gu L, Zhu M, Dai H, Zhang W, Qian J. Clinical outcome of twice-weekly hemodialysis patients in shanghai. Blood Purif. 2012;33(1-3):66-72.

30. Stankuviene A, Ziginskiene E, Kuzminskis V, Bumblyte IA. Impact of hemodialysis dose and frequency on survival of patients on chronic 
hemodialysis in Lithuania during 1998-2005. Medicina (Kaunas). 2010:46(8):516-21.

31. Supasyndh O, Satirapoj B, Seenamngoen S, Yongsiri S, Choovichian P, Vanichakarn S. Nutritional status of twice and thrice-weekly hemodialysis patients with weekly Kt/N > 3.6. J Med Assoc Thail. 2009;92(5):624-31.

32. Lin YF, Huang JW, Wu MS, Chu TS, Lin SL, Chen YM, Tsai TJ, Wu KD.

Comparison of residual renal function in patients undergoing twice-weekly versus three-times-weekly haemodialysis. Nephrology (Carlton). 2009;14(1):59-64.

33. Tzamaloukas AH, Vanderjagt DJ, Agaba El, Ma I, Lopez A, Tzamaloukas RA, Murata GH, Glew RH. Inadequacy of dialysis, chronic inflammation and malnutrition in Nigerian patients on chronic hemodialysis. Int J Artif Organs. 2006;29(11):1067-73

34. Tangvoraphonkchai K, Davenport A. Incremental Hemodialysis - a European perspective. Semin Dial. 2017:30(3):270-6.

35. Ghahremani-Ghajar M, Rojas-Bautista V, Lau WL, Pahl M, Hernandez M, Jin A, Reddy U, Chou J, Obi Y, Kalantar-Zadeh K, et al. Incremental Hemodialysis: the University of California Irvine experience. Semin Dial. 2017;30(3):262-9.

36. Culleton BF, Walsh M, Klarenbach SW, Mortis G, Scott-Douglas N, Quinn RR, Tonelli M, Donnelly S, Friedrich MG, Kumar A, et al. Effect of frequent nocturnal hemodialysis vs conventional hemodialysis on left ventricular mass and quality of life: a randomized controlled trial. JAMA. 2007:298(11):1291-9.

37. Daugirdas JT, Greene T, Rocco MV, Kaysen GA, Depner TA, Levin NW, Chertow GM, Ornt DB, Raimann JG, Larive B, et al. Effect of frequent hemodialysis on residual kidney function. Kidney Int. 2013;83(5):949-58.

38. Chan CT, Greene T, Chertow GM, Kliger AS, Stokes JB, Beck GJ, Daugirdas JT, Kotanko P, Larive B, Levin NW, et al. Determinants of left ventricular mass in patients on hemodialysis: frequent Hemodialysis network (FHN) trials. Circ Cardiovasc Imaging. 2012;5(2):251-61.

39. Chertow GM, Levin NW, Beck GJ, Depner TA, Eggers PW, Gassman JJ, Gorodetskaya I, Greene T, James S, Larive B, et al. In-center hemodialysis six times per week versus three times per week. N Engl J Med. 2010:363(24):2287-300

40. National Kidney Foundation. KDOQI clinical practice guideline for Hemodialysis adequacy: 2015 update. Am J Kidney Dis. 2015;66(5):884-930.

41. van Olden RW, van Acker BA, Koomen GC, Krediet RT, Arisz L. Time course of inulin and creatinine clearance in the interval between two haemodialysis treatments. Nephrol Dial Transplant. 1995;10(12):2274-80.

42. Shafi T, Michels WM, Levey AS, Inker LA, Dekker FW, Krediet RT, Hoekstra T, Schwartz GJ, Eckfeldt JH, Coresh J. Estimating residual kidney function in dialysis patients without urine collection. Kidney Int. 2016;89(5):1099-110.

\section{Submit your next manuscript to BioMed Central and we will help you at every step:}

- We accept pre-submission inquiries

- Our selector tool helps you to find the most relevant journal

- We provide round the clock customer support

- Convenient online submission

- Thorough peer review

- Inclusion in PubMed and all major indexing services

- Maximum visibility for your research

Submit your manuscript at www.biomedcentral.com/submit

C Biomed Central 